\title{
Pregnancy in Non-Communicating Unicornuate Uterus: Diagnosis Difficulty and Outcomes - a Case Report
}

\section{Gestação em útero unicorno não comunicante: dificuldade diagnóstica e desfechos - relato de caso}

\author{
Camila Silveira de Souza ${ }^{1}$ Gabriela Gindri Dorneles ${ }^{1}$ Giana Nunes Mendonça ${ }^{1}$ \\ Caroline Mombaque dos Santos ${ }^{1}$ Francisco Maximiliano Pancich Gallarreta ${ }^{1}$ Cristine Kolling Konopka ${ }^{1}$ \\ ${ }^{1}$ Department of Gynecology and Obstetrics, Universidade Federal de \\ Santa Maria, Santa Maria, Rio Grande do Sul, Brazil \\ Address for correspondence Cristine Kolling Konopka, MD, PhD, \\ Universidade Federal de Santa Maria, Avenida Roraima, 1000, prédio \\ Rev Bras Ginecol Obstet 2017;39:640-644. \\ 26, sala 1333, Camobi, 97105-900, Santa Maria, RS, Brazil \\ (e-mail: cristine.ufsm@gmail.com).
}

\begin{abstract}
Keywords

- uterus

- abnormalities

- pregnancy

- parturition

- pregnancy complications

\section{Resumo}

\section{Palavras-chave}

- útero

- anormalidades

- gravidez

- parto

- complicações na gravidez

Approximately 1 in every 76,000 pregnancies develops within a unicornuate uterus with a rudimentary horn. Müllerian uterus anomalies are often asymptomatic, thus, the diagnosis is a challenge, and it is usually made during the gestation or due to its complications, such as uterine rupture, pregnancy-induced hypertension, antepartum, postpartum bleeding and intrauterine growth restriction (IUGR). In order to avoid unnecessary cesarean sections and the risks they involve, the physicians should consider the several approaches and for how long it is feasible to perform labor induction in suspected cases of pregnancy in a unicornuate uterus with a rudimentary horn, despite the rarity of the anomaly. This report describes a case of a unicornuate uterus in which a pregnancy developed in the non-communicating rudimentary horn and the consequences of the delayed diagnosis.

Aproximadamente 1 em cada 76 mil gestações se desenvolvem em útero unicorno sem comunicação com o colo uterino. Anomalias müllerianas uterinas são, na maioria das vezes, assintomáticas, tornando difícil o diagnóstico, que geralmente é esclarecido durante a gestação ou por conta das complicações gestacionais, como ruptura uterina, hipertensão gestacional, parto pré-termo, hemorragias pós-parto e crescimento intrauterino restrito (CIUR). Com o intuito de evitar cesáreas desnecessárias e os riscos que esse procedimento envolve, considerações devem ser feitas quanto aos diferentes métodos utilizados, e por quanto tempo é viável induzir o parto na possibilidade de útero não comunicante, mesmo sendo uma anomalia rara. Este relato descreve um caso de uma gestação que se desenvolveu em um útero unicorno não comunicante com o colo uterino e as consequências do diagnóstico tardio.
\end{abstract}

received

April 13, 2017

accepted

August 22, 2017

published online

October 3, 2017
DOI https://doi.org/

10.1055/s-0037-1607046. ISSN 0100-7203.
Copyright $\odot 2017$ by Thieme Revinter

Publicações Ltda, Rio de Janeiro, Brazil
License terms

(c) (i) $\ominus$ (\$) 


\section{Introduction}

Female reproductive tract congenital anomalies may involve the uterus, the cervix, the fallopian tubes, or the vagina. The obstetric and gynecologic health of the woman may be adversely affected, depending on the specific defect. A complex series of events is needed in order for the female reproductive tract to develop normally, and the failure of any part of this process may result in a congenital anomaly. ${ }^{1}$

The most common müllerian anomalies affect the uterus. Congenital uterine anomalies are present in 1 to $10 \%$ of the unselected population, 2 to $8 \%$ of infertile women, and 5 to $30 \%$ of women with a history of miscarriage. ${ }^{2}$ In 1988 , the American Society for Reproductive Medicine classified the congenital uterine anomalies focusing on the major categories of uterine anomalies (-Fig. 1). ${ }^{3}$ This classification is divided into seven main categories: hypoplasia and agenesis, unicornuate, didelphys, bicornuate, septate, arcuate, and diethylstilbestrol (DES)-related. ${ }^{3}$

Unicornuate uterus constitutes roughly $5 \%$ of the constellation of uterine malformations. ${ }^{2}$ This abnormality results from a partial or complete failure in the development of one of the paramesonephric ducts. There are four described variations of unicornuate uterus: an isolated unicornuate uterus with no contralateral structure, and three variations with a contralateral rudimentary horn. The rudimentary horn may have a cavity that communicates or is sealed off from the primary uterine cavity. ${ }^{2}$
Approximately 1 in every 76,000 pregnancies develops within a unicornuate uterus with a rudimentary horn, with an associated ectopic pregnancy in $83 \%$ of these cases. ${ }^{4,5}$ When a pregnancy occurs in an obstructed or rudimentary uterine horn, it rarely reaches term. Other obstetrical complications are uterine rupture in $50-80 \%$ of the cases, as well as cervical incompetence, pregnancy-induced hypertension, antepartum, intrauterine growth restriction (IUGR) and postpartum bleeding. ${ }^{5}$ Thus, the many complications that may affect the woman and the fetus are an indication of the importance of an early diagnosis of müllerian anomalies.

The objective of the present study is to report a case of a diagnosis of a woman on the 44th week of gestation with a unicornuate uterus with a non-communicating rudimentary horn and its outcomes.

\section{Case Description}

A 22-year-old woman, primigravida, at 44 weeks and 3 days of gestational age according to a previous ultrasound performed on the 18th week of gestation (17 weeks and 3 days), reported she regularly attended the routine prenatal care provided in her hometown's basic health unit. The pregnancy lasted this long due to a misdiagnosis of IUGR at the 40th week of gestation, when the fetal biometry suggested 36 weeks of gestation. The patient was transferred to a tertiary referral hospital reporting reduction of fetal movement and, during the prenatal care, the fetal heart rate was not audible. Upon

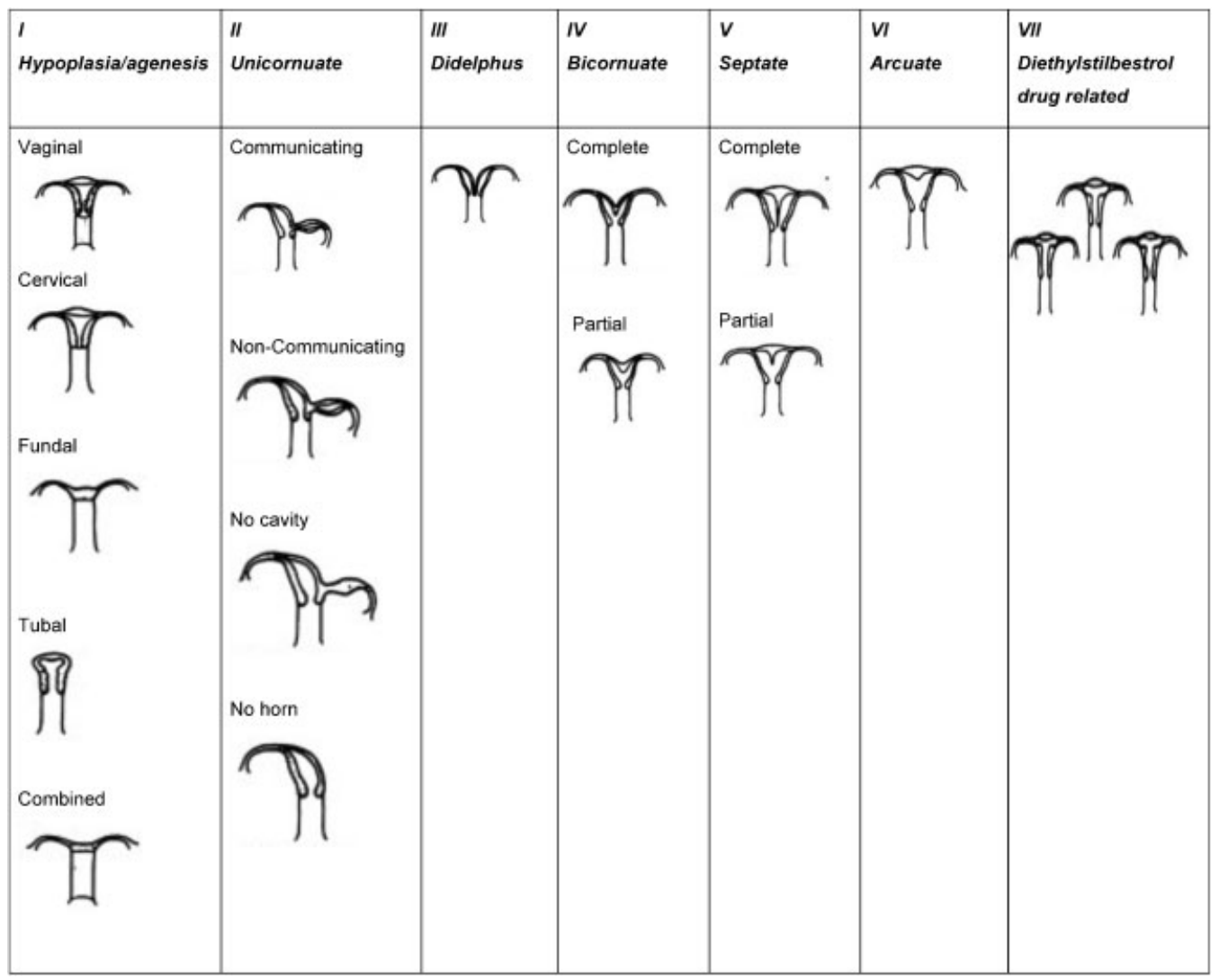

Fig. 1 American Society for Reproductive Medicine classification system for müllerian anomalies. 
admission, the patient was clinically asymptomatic and stable, presenting no uterine contractions and no cervical dilatation. The symphysis-fundal height was lower than expected $(30 \mathrm{~cm})$ for the date of the gestation, and upon auscultation, the fetal heart rate was inaudible. The patient was submitted to laboratorial and ultrasound exams. The obstetric ultrasonography showed absence of fetal heart rate (fetal death), as well as, size, growth and weight that were abnormal considering the gestational age. Initially, labor induction was attempted. During four days, the patient was submitted to different methods of labor induction. At first, she was administered $25 \mathrm{mcg}$ of vaginal misoprostol every 4 hours, with no results after the 7th dose. After that, she was administered an infusion of sodium chloride $0.9 \%$ with 5 UI of oxytocin, followed by increasing concentrations of the same infusion. At that moment, the cervix was still unaltered, despite the onset of contractions. Prostaglandin (misoprostol) was administered a second time, in a double-dose scheme (50 mcg vaginally every 4 hours), with seven doses being administered again. Cervical effacement with no dilatation was observed. As a last attempt, a foley catheter was used, followed by a macro infusion of oxytocin in increasing doses. The interventions were unsuccessful, and the patient underwent a cesarean section. During birth, there was an absence of amniotic fluid, and the birth resulted in a lifeless fetus, which was suggestive of a bicornuate uterus with pregnancy development in the horn that does not communicate with the vagina (-Fig. 2 ). Intraoperatively, an adherent placenta accreta and a hypotonic uterus were observed, and high doses of intravenous oxytocin as well as methergine had to be administered in the uterine horn.

At the postpartum follow-up, the patient had a good recovery, and at the 13th day after the cesarean section she was submitted to a transvaginal ultrasound. The ultrasonography image suggested two possible diagnoses: a unicornuate uterus with a non-communicating rudimentary horn or a bicornuate uterus. A magnetic resonance imaging (MRI) scan was necessary to clarify the diagnosis. The MRI description

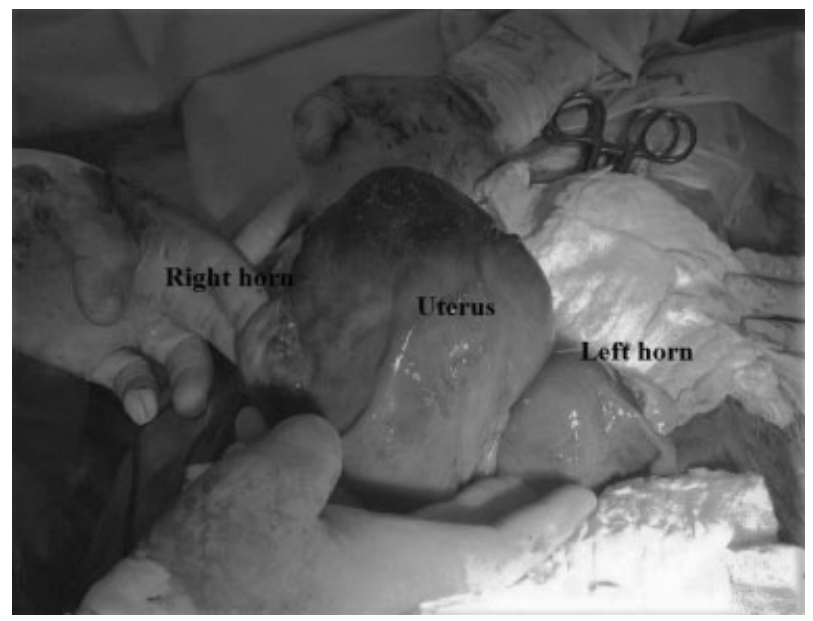

Fig. 2 An intraoperative indication of a bicornuate uterus with pregnancy development in the horn that does not communicate with the vagina. Source: Photograph courtesy of Giana Nunes Mendonça, MD, Universidade Federal de Santa Maria, 2017.

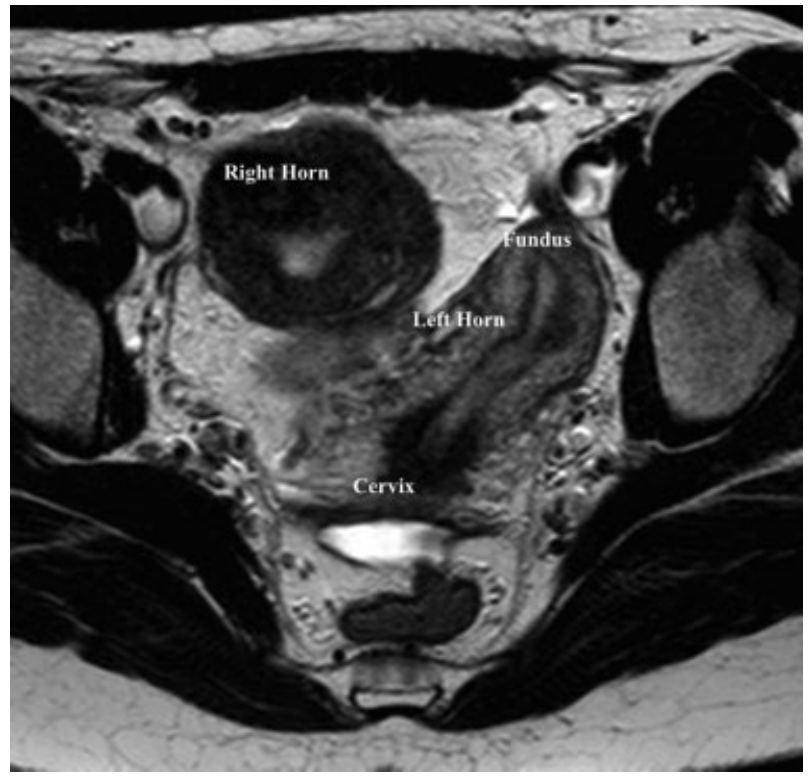

Fig.3 A magnetic resonance imaging (MRI) scan, axial plan weighted in T2 spin echo, showing double uterine fundus and the body of the uterus. The right side enlarged component presents heterogeneous contents. There is no communication with the cervix.

showed a double fundus and the body of the uterus; however the right side component was defined as a non-communicating rudimentary horn, corroborating the hypothesis of noncommunicating unicornuate uterus (-Figs. 3 and $\mathbf{4}$ ).

\section{Discussion}

Pregnancy in a rudimentary uterine horn is rare and often presents poor outcomes. The incidence of pregnancy in a

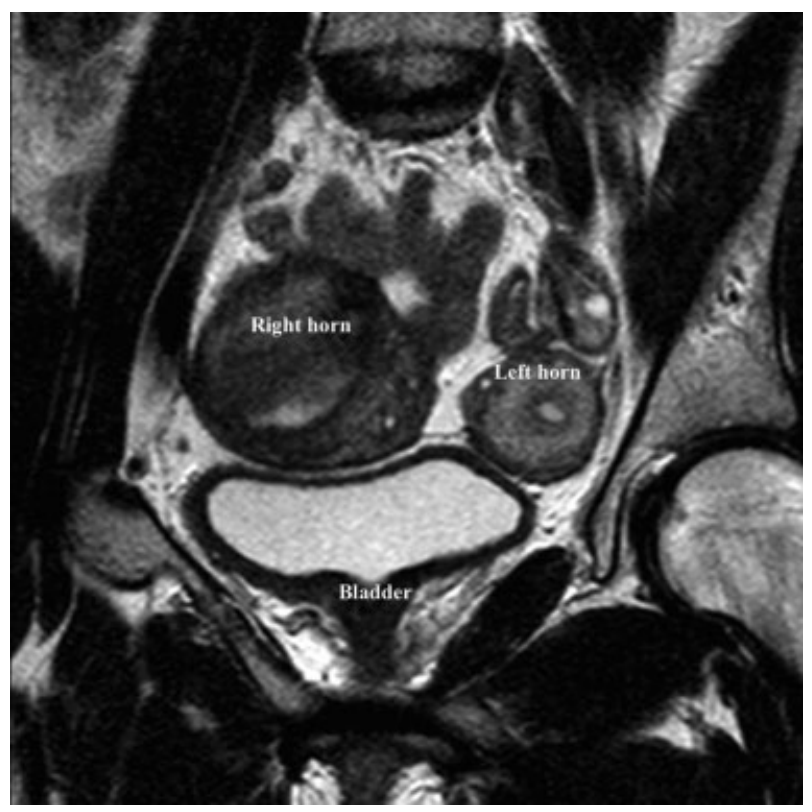

Fig. 4 An MRI scan, coronal plan weighted in T2 spin echo, showing double uterine fundus and the body of the uterus. The right side enlarged component presents heterogeneous contents. 
rudimentary uterine horn is of $1 / 100,000-1 / 140,000$ pregnancies, and most are cases of non-communicating horns. ${ }^{6}$ Horn rupture occurs in $80-90 \%$ of these pregnancies during the second trimester, and $10 \%$ of the pregnancies proceed to term, but only $2 \%$ reach fetal survival. Rupture frequently results in massive hemoperitoneum, leading to fetal demise and maternal compromise. ${ }^{6}$

A unicornuate uterus with a rudimentary horn is a rare type of müllerian duct malformation that is a consequence of a fusion defect in a malformed duct with its contralateral duct. These ducts can be built-in or not by a fibromuscular band which connects the horns of the ducts. ${ }^{6}$ The case described here corresponds to one of the $80-90 \%$ of situations in which the horns are non-communicating, in other words, the ducts are not connected to this fibromuscular band. ${ }^{6}$ Despite being common among unicornuate uterus, the outcomes of this anomaly described throughout gestation in the case presented here were rare and, at the same time, a sort of alert.

Pregnancy in non-communicating rudimentary horn is a rare form of gestation that occurs due to the trans peritoneal migration of the sperm or the zygote. ${ }^{6}$ Its incidence is of approximately $1 / 100,000$ to $1 / 140,000$ pregnancies. $^{7}$

When gynecological symptoms such as abdominal pain, dysmenorrhea, retrograde menstruation and infertility are present, non-communicating rudimentary horn can be suspected. However, the diagnosis is unlikely before the anomaly causes reproductive problems, and the diagnosis is usually made as an incidental finding during a routine prenatal ultrasound. $^{8}$

The first line diagnostic modality to investigate pelvic pathologies is transvaginal ultrasonography. ${ }^{8}$ Yet, due to its sensitivity, the ultrasound detects less than three fourths of the cases, and this detection declines as the pregnancy advances. ${ }^{9}$ According to Goel et al ${ }^{6}$, only $5 \%$ of the reported cases of rudimentary horn pregnancies were diagnosed preoperatively. The enlarging pregnant horn tends to displace the contralateral half of the uterus, making it difficult to demonstrate this uterine anomaly in the transabdominal scan. ${ }^{6} \mathrm{~A}$ three-dimensional ultrasound or an MRI scan are more likely to determine the full delineation of the anomaly. The MRI has become the gold standard for the evaluation of congenital uterine anomalies. ${ }^{8}$

When pregnancy occurs, characteristics such as the variable thickness of the rudimentary horn musculature, a dysfunctional endometrium, and poor distensibility of the myometrium lead to the life-threatening condition usually observed during the second trimester of gestation: rupture of the rudimentary horn. ${ }^{6}$ In a study conducted by Goel et $\mathrm{al}^{8}$ between April of 1994 and March of 2004 with 18 patients diagnosed by laparotomy with unicornuate uteri with non-communicating rudimentary horns, 7 patients had pregnancies in the noncommunicating rudimentary horns, and, 5 presented in a state of shock due to rudimentary horn rupture. ${ }^{6}$

In accordance with the case reported here, a similar case, but in which the outcome was fetal survival, was reported by Pal et $\mathrm{al}^{7}$ in 2006. The authors also mentioned the difficulty of making a diagnosis by ultrasound. In that case, the diagnosis was made after a clinical abruption followed by a laparotomy, which confirmed the hypothesis of rudimentary non-communicating horn. ${ }^{7}$ Since most uterine anomalies are asymptomatic, the diagnosis is usually delayed, often made through an exploratory laparotomy after pregnancy or due to uterine rupture, for example. ${ }^{4}$

Furthermore, considering the decreased blood supply and defective endometrium in a pregnancy located in a rudimentary horn, missed abortion is commonly observed. If the pregnancy develops, it usually goes through the first trimester uneventfully, as the rudimentary horn is thicker than the fallopian tube. ${ }^{6}$

On the other hand, several poor pregnancy developments have been suggested as a consequence of uterine anomalies. First-semester abortion and IUGR might be some of the outcomes caused by the abnormal uterine blood flow (due to absent or abnormal uterine or ovarian arteries) in cases of unicornuate uterus. Second-trimester abortions and preterm deliveries are also likely outcomes caused by the decrease in muscle mass in the unicornuate uterus and cervical incompetence. ${ }^{5}$ In this case report, IUGR was observed during gestation, but it was not well-detected or diagnosed early enough. As a result, post-term gestation and fetal death occurred.

Thus, considering this rare anomaly and all the infrequent events caused by it, the case described here involves a post-term gestation with regular routine prenatal care until the absence of the fetal heart rate was detected on the 44th week of gestation; the patient did not present clinical instability, which was an indication that the uterus had not been ruptured, fortunately. Although it is difficult to truly estimate the incidence of the complications in a noncommunicating rudimentary horn pregnancy considering the scarce data available, and considering most cases described in the literature, ${ }^{6}$ it became clear that the outcomes of the fetus and the pregnant woman in the case described here were unusual.

Cesarean delivery and its risks are widely debated. According to Spong et al, ${ }^{10}$ cesareans are primarily attempted to reduce the overall morbidities related to cesarean delivery. Previous cesarean deliveries increase risks such as uterine rupture, intraoperative complications (placenta previa, accreta, increta, percreta) or adhesions of the uterus, bowel and bladder, for subsequent pregnancies. Moreover, abnormal bleeding or trauma during surgery might be observed. ${ }^{11}$

Nevertheless, physicians have to consider how long labor induction should be performed in order to avoid a cesarean section. ${ }^{10}$ Studies have shown that women undergoing labor induction may remain in the latent phase for at least 6 hours, or for 12 hours or longer in $50 \%$ and $20 \%$ of the cases respectively.$^{10}$ After more than 12 hours of labor induction, there is much debate about whether the procedure should continue or to "rest" the patient with no progress. According to Spong et al, ${ }^{10}$ when neither the maternal nor the fetal conditions are worsening with time, published trials allowed cervical ripening over a period ranging from a single dose to several doses over two days, despite the fact that this is still a common obstetrical dilemma. In the case reported here, considering the patient characteristics (young age and first pregnancy) and the fetal death condition, a prolonged and diversified labor induction was attempted to avoid a cesarean section. 
In conclusion, class II müllerian anomalies are rare, with an estimated incidence of $\sim 1$ in every 300,000 pregnancies. $^{12}$ Thus, although cesarean section avoidance can be justified by a very low probability of non-communicating unicornuate uterus, caution should be taken when uterine anomalies are suspected during the ultrasound pelvic examination in early pregnancies, as well as when IUGR is detected with no evidence of risk factors. Further investigations using threedimensional ultrasonography and/or the MRI should be considered to define the precise characteristics of the uterine anomalies. In the case described here, these modalities might have helped avoid the several methods of labor induction, including misoprostol, which leads to a high risk of uterine rupture, as well as fetal death and maternal hazards.

Conflicts of Interest

The authors have no conflicts of interest to declare.

\section{References}

1 Rackow BW, Arici A. Reproductive performance of women with müllerian anomalies. Curr Opin Obstet Gynecol 2007;19(03): 229-237. Doi: 10.1097/GCO.0b013e32814b0649

2 Reichman D, Laufer MR, Robinson BK. Pregnancy outcomes in unicornuate uteri: a review. Fertil Steril 2009;91(05):1886-1894. Doi: $10.1016 /$ j.fertnstert.2008.02.163

3 The American Fertility Society classifications of adnexal adhesions, distal tubal occlusion, tubal occlusion secondary to tubal ligation, tubal pregnancies, müllerian anomalies and intrauterine adhesions. Fertil Steril 1988;49(06):944-955. Doi: 10.1016/ S0015-0282(16)59942-7
4 Samuels TA, Awonuga A. Second-trimester rudimentary uterine horn pregnancy: rupture after labor induction with misoprostol. Obstet Gynecol 2005;106(5 Pt 2):1160-1162

5 Caserta D, Mallozzi M, Meldolesi C, Bianchi P, Moscarini M. Pregnancy in a unicornuate uterus: a case report. J Med Case Reports 2014;8:130. Doi: 10.1186/1752-1947-8-130

6 Goel P, Aggarwal A, Devi K, Takkar N, Saha PK, Huria A. Unicornuate uterus with non-communicating rudimentary horn - different clinical presentations. J Obstet Gynaecol India 2005;55(02):155-158

7 Pal K, Majumdar S, Mukhopadhyay S. Rupture of rudimentary uterine horn pregnancy at 37 weeks gestation with fetal survival. Arch Gynecol Obstet 2006;274(05):325-326. Doi: 10.1007/ s00404-006-0170-y

8 Lovelace D. Congenital uterine anomalies and uterine rupture. J Midwifery Womens Health 2016;61(04):501-506. Doi: 10.1111/ jmwh.12423

9 Garg R, Kaur P, Saini S. Spontaneous rupture of noncommunicating rudimentary horn pregnancy presenting as medical emergency. Int J Med Sci Clin Invent. 2016;3(04):1816-1819. Doi: 10.18535/ijmsci/v3i4.13

10 Spong CY, Berghella V, Wenstrom KD, Mercer BM, Saade GR. Preventing the first cesarean delivery: summary of a joint Eunice Kennedy Shriver National Institute of Child Health and Human Development, Society for Maternal-Fetal Medicine, and American College of Obstetricians and Gynecologists Workshop. Obstet Gynecol 2012;120(05):1181-1193. Doi: 10.1097/AOG.0b013e3182704880

11 Clark EA, Silver RM. Long-term maternal morbidity associated with repeat cesarean delivery. Am J Obstet Gynecol 2011;205(6, Suppl)S2-S10. Doi: 10.1016/j.ajog.2011.09.028

12 van der Veen NM, Brouns JF, Doornbos JP, van Wijngaarden WJ. Misoprostol and termination of pregnancy: is there a need for ultrasound screening in a general population to assess the risk for adverse outcome in cases of uterine anomaly? Arch Gynecol Obstet 2011;283(01):1-5. Doi: 10.1007/s00404-010-1561-7 